\title{
OPERATIONAL RESEARCH IN ADVERTISING
}

$\mathrm{R}$ ESEARCH into advertising has been much intensified in recent years, and it is timely to find that a paper on the subject has been read by Mr. J. Maitland at this year's meeting of Section F (Economics) of the British Association.

The problem studied may be very simply stated. It is to determine the relationship, if any, between the amount of advertising (concerning some article or service) and the response to it. It is supposed that the problem of defining measures of the 'amount of advertising' and the 'response' has been settled previously. Advertising is considered as an example of a stimulus; this stimulus is regarded as the input, and the response as the output. Thus we have an input-output situation of the type well known in experimental psychology, and this leads to a model based on a physiological analogy. Data were taken from five sets of advertising campaigns : (1) advertisement, by way of technical journal announcements and leaflets mailed to medical practitioners, of a vitamin product; (2) mailed leaflets based on the membership lists of learned societies and professional organizations; (3) service recruiting by means of newspaper advertisements, type $1 ;(4)$ as in (3), type 2 ; (5) radio equipment advertised in daily newspapers. The amount of advertising, $A$, was measured in terms of quantities such as the number of announcements or journal issues or leaflets distributed, while the response, $R$, was measured in terms of the number of inquiries.

In order to set up a model of the input-output system, three analogies were used-physiological, biological assay and physical.

Physiological analogy. In this case a linear relationship between $R$ and in $A$ would be expected. By plotting the data referred to above such a relationship was reasonably suggested. The method of least squares was used in fitting the curve. The linear relationship, $R=a \ln A+b$, where $a$ and $b$ are constants, suggested that: (1) there is a threshold value of advertising below which there is no appreciable response; (2) as the amount of advertising increases a state of saturation is reached in the sense that further advertising produces a negligible response.

These results permit an estimation of the point at which the marginal gain becomes too small to justify increased advertising.

An alternative formulation is in terms of the law of diminishing returns (see Zentler and Ryde. Management Science, 2, 337; 1956) and it is found that the response $R$ may be related to the expenditure. $x$, on promotion by an equation of the form:

$$
R=R^{\prime} y^{2} /\left(1+y+y^{2}\right)
$$

where $y=x / b$ and $R^{\prime}$ and $b$ are constants.

The analogy of biological assay. This is the model to use if one is interested in relative rather than absolute response. The numerical data available were analysed to determine the increase in the proportion of the population responding to a prescribed increase in the amount of advertising.

Physical analogy. Here reference is made to the work of Vidale and Wolfe (Operations Research, $5,370 ; 1957)$, who introduced the concept of a saturation-level as the practical limit of sales that may be generated as promotional activity is increased in intensity. The mathematics of this case leads to an equation which implies an exponential rise of $R$ to a maximum as advertising intensity is increased. Thus the analogy is that of the charging of an electrical condenser.

The proportions of the population responding to varying degrees of stimulus are compared for the various methods used. There is little difference between the results obtained by the logarithmic law and by the probit analysis, although the former involves less computation. The simplest form of the theory of Zentler and Ryde is not very satisfactory, and a more complex form is inconvenient in comparison with the other alternatives.

\section{ATOMIC POWER IN CANADA}

$\mathrm{D}$ URING the Second World War, Chalk River, Ontario, was selected by the Canadian Atomic Energy Project as the site for the major research reactor, NRX, which was to be a high-flux reactor fuelled with natural uranium metal, moderated with heavy water and cooled with natural water. The low-energy heavy-water reactor, ZEEP, was first constructed on the site in 1945 and this served as a check on the design of NRX. In 1947, NRX began to operate with a heat output of 30 megawatts. A more powerful reactor, NRU, fuelled with natural uranium metal but both cooled and moderated with heavy water, was then constructed on the site, and this came into operation in 1957 at 200 megawatts. Like NRX, NRU was designed to take advantage of the high neutron flux produced for the production of plutonium and radioactive isotopes for research purposes, but both reactors operate at low temperature and pressure, and in neither is it possible to employ usefully the heat produced.

An increasing proportion of the research and development work at Chalk River was, however, devoted from 1951 onwards to problems related to the provision of economic atomic power, and although direct progress was somewhat slowed down by the accident which occurred to the NRX reactor in December 1952, the successful reconstruction of the reactor and its power increase to 40 megawatts brought valuable confidence in the long-term maintenance and the safety of heavy-water moderated reactors for power. The use of heavy water leads to good economy of neutrons and is one of the best long-term prospects for cheap nuclear power. The gas-cooled, graphite-moderated reactors in use in Great Britain required less development work and. therefore, were brought into operation sooner, but the price at which they produce electricity is for most 
places in Canada much too high to compete with other available sources of electricity.

Early in 1954 a group, known as the Nuclear Power Branch, was set up in Chalk River to study the design of nuclear reactors for the economic production of power, and a demonstration reactor, known as NPD-2 and proposed by the Branch, is now under construction by the Canadian General Electric Company at Des Joachims on the Ottawa River and is expected to come into operation during 1961. In September 1955, after the decision had been taken to build NPD, the Branch began a study of a full-scale nuclear plant. The results of this study were described in a report in May 1957, but which was given only limited circulation.

However, a booklet* based on the report, giving the background history of the Canadian project and describing in detail the plant designed by the Nuclear Power Branch, has been prepared by J. E. Woolston and has recently been issued. In the first two sections the possible demand for nuclear power in Canada and the general approach to the study including the cost

* Atomic Energy of Canada Ltd. The Canadian Study for a FullScale Nuclear Power Plant. Pp. 64. (Chalk River, Ontario: Atomi Energy of Canada, Ltd., 1958.) 1.50 dollars. target for a competitive nuclear power plant are discussed. The third section deals in detail with the proposed reactor, which has a thermal power of 794 megawatts and a net electrical output of 200 megawatts. Slugs of natural uranium oxide are used as fuel, and it is cooled and moderated by heavy water. The fuel is housed in horizontal pressure tubes through which the pressurized heavy-water coolant passes. There are 200-250 tubes mounted on a square-lattice with a pitch of one foot. A feature of the design is the high burn-up planned for the unenriched oxide, which is considered to be of greater economic advantage than the improvement of the steam conditions and the rather poor thermal efficiency of the plant. The final sections in the report deal with the range of studies carried out by the Branch and the alternative systems investigated; pertinent Chalk River experience; and the estimate of cost of the nuclear plant and its operation. The names of the members of the staff of the Nuclear Power Branch who participated in the studies leading to the proposed reactor are listed in one appendix, and in another complete data on the main components of the reactor are set out.

\section{RESEARCH IN ALBERTA}

$\mathrm{T}$ HE thirty-eighth annual report of the Research Council of Alberta* records generally satisfactory progress in all projects during the calendar year 1957 and also in the recruitment of staff of high calibre. A feature of the year was the development of the geological research and survey operations which led to the initiation of survey operations in the north-east corner of Alberta in the Precambrian Shield area. The expansion of the co-operative basic cloud physics research programme with particular reference to the problem of hail in Western Canada was also noteworthy. In the work on coal, evidence was obtained that the calorific value decreases considerably when coals were exposed to the air for prolonged periods, and the thermograms of several coal fractions and of three dated fossil woods were determined. In other differential thermal analysis studies it was observed that sulphur dioxide can modify extensively the course of the pyrolysis of coal. A study of the grindability of coal was completed, and considerable progress made in studies of fluidized coal carbonization.

A theoretical analysis of the flow of stratified water and oil in horizontal pipe-lines agreed well with experimental observations, and progress is reported in the catalytic desulphurization and oxidation with nitric acid of organic sulphur compounds. The study of detailed trace metal and component geochemistry of four major and several minor oilfields was completed; engineering studies continued on the hightemperature pyrolysis of natural gas and a process was developed for removing nitrogen from natural gas. An infiltration study on a river terrace south of Camrose indicated that certain surface water supplies in Alberta can be purified by this technique. Results obtained in studies on electrosomatic flow into clay soils provide a starting point for computing the power

* Research Council of Alberta. Thirty-eighth Annual Report, 1957. (Report No. 77.) Pp. 56. (Edmonton: Queen's Printer, 1958.) requirements necessary to reduce the moisture content of soil by this method, and besides work on the strength, stability and compaction of a base cover material, the instability conditions in bridge abut. ments were investigated and the problem of frost action received continued attention.

The biological cycles programme, which was brought to a virtual close by the death of Dr. W. Rowan, has indicated a rather dramatic increase in grouse and rabbit populations in many areas. Studies on the nutritive value of rape-seed oil indicate that fermenting and drying ground rape-seed prior to oil extraction remove two of the toxic factors and that the high temperatures used in extracting the oil may be partly responsible for the varying feeding value of commercial rape-seod oil meals. The adsorption areas of acetylene, ethylene and ethane on Charcoal No. 2222 have been measured, and it appears that the less 'active', finer-pored charcoal may be more valuable for certain dynamic separations of gases, as in chromatographic column, a technique which is proving of increasing value. A weather radar set has been installed at Penhold and used to follow the detailed courses of precipitating storms within 100 miles, while the hail-reporting network now covers some 15,000 square miles in central Alberta. Lapsetime cloud photography was also expanded and the commercial hail-suppression programme operated over 400 square miles in the southern part of the hail project area. Ground-water conditions were surveyed in five districts and the answering of inquiries is an important part of the ground-water programme. The palæobotanical laboratory continued to be concerned chiefly with describing and cataloguing the Edmonton Paskapoo fossil floras in central Alberta, and microslides have now been made of all the species of modern conifer woods in the type collection. A list of publications is appended. 